\title{
Intrinsic Religiosity, Personality Traits, and Adolescent Risky Behaviors
}

\section{Introduction}

There is considerable empirical evidence to indicate that the behavioral outcomes of people who hold religious beliefs are different from those who do not (e.g., Iannacone, I998; Campante and Yanagizawa-Drott, 2015). ${ }^{1}$ Individuals who score higher on measures of religiosity tend to score better in a breadth of outcomes, such as health and other measures of well-being. There is also a literature that suggests that there are certain personality traits that are correlated with such outcomes (e.g. Mendolia and Walker, 20I4, and references therein). Religiosity may well be positively correlated with some of these traits (and perhaps negatively correlated with others). To the extent that favorable health and well-being outcomes might be due to either having favorable personality traits, or having a high degree of religiosity, or both, then there is a case for unravelling the importance of each. Indeed, if they do complement each other, then the case of cultivating these traits might be even greater in places where there is a high degree of religiosity. $^{2}$

Our objective is to estimate the strength of the association between religiosity and the propensity to engage in risky health behaviors among teenagers, allowing for psychological traits. These behavioral outcomes pertain to the consumption of alcohol, tobacco, and cannabis; sexual intercourse; and physical violence. Such risky health behaviors may be associated with chronic health conditions, low educational achievements in adolescence (Sabia and Rees, 2009), future morbidity, and premature mortality (Gruber, 2000; Kipping et al., 20I2). ${ }^{3} \mathrm{We}$

\footnotetext{
${ }^{1}$ See Hungerman (2014) and the references therein, particularly those listed in his first footnote.

${ }^{2}$ As in Iannaccone (1998), and much of the literature, we remain silent on the "validity of religious beliefs or authenticity of religious institutions".

${ }^{3}$ See Cawley and Ruhm (20II) for a review of the findings in these areas.
} 
focus on risky health behavior in adolescence, in particular, because of the potential long term consequences ${ }^{4}$.

In contrast to the previous literature, we adopt a fixed-effects (FE) regression framework to control for individual- and school-level, time-invariant, unobserved heterogeneity. In addition, we examine the simultaneous roles played by religiosity and personality traits in explaining these behavioral outcomes. These personality traits include work ethic, locus of control, and self-esteem. We estimate these complex effects using a treatment-effects inverse-probability-weighted regression-adjustment (IPWRA) framework developed by Imbens and Wooldridge (2009) and recently implemented by Cattaneo et al. (2013).

We contribute to the literature on the determinants of adolescent risky health behaviors in several ways. First, we extend the literature on the relationship between religiosity and behaviors using a measure of intrinsic religiosity (namely, the importance of religion in one's life). Previous research has instead looked at participation in religious activities which we think of as a measure of extrinsic religiosity (e.g., Gruber (2005) and Mellor and Freeborn (20II)). We take the view that intrinsic religiosity is a better indicator of the role that religion per se plays in an individual's decisions and attitudes. It captures the intensity of individual beliefs rather than behaviors that could potentially be imposed by parental and societal expectations. ${ }^{5}$ Second, we also differentiate ourselves from earlier work by specifically focusing on the role that religiosity and non-cognitive personality traits play. ${ }^{6}$ Finally, we separately account for individual- and school-level unobserved heterogeneity.

\footnotetext{
${ }^{4}$ See Gruber (2000) for an analysis of youth risky health behaviour from an economic perspective and Cawley and Ruhm (2OII) for an analysis of economic concepts that relate to health behaviours.

${ }^{5}$ One could argue that intrinsic religiosity may be affected by external factors as well; but, since it is essentially private or hidden, it more likely represents an individual's true feelings about religion.

${ }^{6}$ See Heckman et al. (2006), Chiteji (20I0), Cobb-Clark et al. (20I4), and Mendolia and Walker (20I4), showing that personality traits have a substantial effect on the probability of engaging in risky health behaviors.
} 
Our results show that a high level of religiosity together with a high level of work ethic is strongly associated with a lower propensity to engage in risky behaviors. There is, of course, the risk that potential confounders may affect our econometric modeling, even when we use individual FE estimation, since this only deals with bias associated with time-invariant confounders. Hence, while the results can be taken as further evidence of a robust relationship between intrinsic religiosity and risky behavioral outcomes, we are not able to draw strong causal inferences.

Our results are relevant for the vast majority of countries where the population includes a nontrivial share of religious people but, since the data come from a survey of English youth, it is especially relevant for England and the rest of the UK. In this context, the prevalence of risky behaviors in England is higher than similar OECD countries. For example, the use of cocaine in the UK is $220 \%$ higher than the EU26 average, and the use of ecstasy is more than double the EU26 figure. The UK has one of the highest teenage pregnancy rates of any developed country (ONS, 20I4), and young people have higher rates of sexually transmitted infections (STIs) than older groups (Public Health England, 20I3).

The impact of the costs of these behaviors for society and for a public universal health care system, such as the National Health Service (NHS) in the UK, is likely to be considerable. Smoking causes around 79,000 preventable deaths each year in England, and is estimated to cost the British economy over £II billion per year (Department of Health, 20I7), including the cost of smoking related hospital admissions; loss in lifetime earnings; and loss in productivity because of absences from work. Similarly, the cost of alcohol for the British society has been estimated to £2I billion per year, including costs from alcohol related crime; loss in productivity; and direct costs to the NHS (Department of Health, 20I6). 
The rest of the paper is organized in the following sections. Section 2 provides a brief review of the most relevant work. Section 3 describes our data, Section 4 outlines our estimation methods, Section 5 presents results, and Section 6 discusses the results.

\section{Related Literature}

Religions may act as "social clubs", proscribe risky behaviors, provide social support, and foster self-control and self-regulation (McCullough and Willoughby, 2009; Hungerman, 20I4). Therefore, religiosity can affect health-related outcomes in a variety of ways. If traits associated with religiosity "protect" individuals from risky behaviors (see, e.g., Mellor and Freeborn, 20II and McCullough and Willoughby, 2009), it becomes important to understand the mechanisms through which this effect materializes.

Endogeneity in the form of self-selection pervades much of the relevant literature. Observed empirical relationships between religiosity and positive behavioral outcomes could be the result of unobserved factors that drive both. Yet, it is difficult to conceive of an experiment that might allow the joint or separate impacts on outcomes of interest, and it is unclear that this is something a researcher would normally find it was considered as ethically acceptable. $^{7}$

Outside of economics, the literature in health and social sciences on this topic is substantial (e.g., Rew and Wong, 2006), but establishing causality remains elusive. Within the economics literature, Gruber (2005) and Mellon and Freeborn (20II) use religious market density as an instrument for religious participation to gain some insight on the causal relationship between religiosity and outcomes of interest. However, religion density may affect risky behaviors through peer effects, and people may self-select where to live based on their

\footnotetext{
${ }^{7}$ Nonetheless, a recent paper by Bryan, Choi, and Karlan (2018) does exactly that.
} 
religious affiliation. Other researchers exploit policy-driven changes in the opportunity cost of religious participation (Gruber and Hungerman, 2008) or differences in religiosity between siblings (Fletcher and Kumar, 20I4). Yet religiosity is often driven by family characteristics, and we are unaware of datasets with sufficient variation in religiosity between siblings to pursue this strategy. Fruehwirth et al. (forthcoming) study the impact of religiosity on depression using peers' religiosity as an instrument for individual religiosity, and, therefore, assume that one's mental health is not directly affected by one's peers' religiosity. A similar peers-of-peers strategy in the context of education can be found in Mendolia, Paloyo, and Walker (20I8). This assumption may be credible in that context, but it would be very hard to use a similar instrument in the context of risky heath behaviors, as it is likely that these will be substantially affected by peers' pressure (including peers' religiosity).

The most directly comparable analyses to our own are the work by Sinha et al. (2007) who use a national US survey of 2004 adolescents, and the study by Fletcher and Kumar (20I4), using discordant siblings in the US Add-Health data. Sinha et al. (2007) estimate the effect of religiosity on the log odds, controlling for self-esteem and a variety of background variables and find strong and statistically significant effects on a range of risky behavioral outcomes. However, they make no attempt to consider the likely bias from omitted unobservables. Fletcher and Kumar (20I4) rely on sibling differences. They find a surprising degree of discordance in sibling religiosity - only $43 \%$ reported the same values. Nonetheless, the paper relies on the sibling differences being exogenous - that is, that once one controls for family FE's the variation is exogenous. This assumption has been the topic of intense debate in the context of twins, even identical ones, and it is not clear that the assumption is innocuous, even though it may be untestable.

We substantially contribute to this literature, by providing evidence of the association between religiosity and risky behaviors and explicitly taking into account individual 
unobservable characteristics, personality traits, and the role of different combinations of these traits and religiosity.

\section{Data and Descriptive Statistics}

This paper uses data from the first four yearly waves of Next Steps, previously known as the Longitudinal Study of Young People in England or LSYPE (Department of Education, 20II). The survey started when the adolescents were in Year 9 at school in 2004 (Age I3-I4). In the first wave, I3,9I4 young people from 647 schools answered a full interview. The attrition rate was low, with response rates ranging from $74 \%$ in Wave 2 to $85-90 \%$ in the following waves. Young people included in LSYPE were selected to be representative of the English population, but specific groups were oversampled — in particular, young people from a low socioeconomic background and from minorities (see Department of Education, 2011). Further details of the data and its structure can be found in Centre for Longitudinal Studies (2018) and in Anders (2014). Our estimation sample includes up to 49,774 observations $^{8}$ (person waves) of adolescents aged $\mathrm{I}^{-}-\mathrm{I} 8$ years old with non-missing information on religiosity and risky behaviors.

Distinguishing between intrinsic religiosity and personality traits is an important aspect in this paper. For example, individuals who say that religion is very important in their life are more likely to have high work ethic, but they are also more likely to have an external locus of control - that is, those with high intrinsic religiosity are more likely to believe that their lives are largely controlled by factors they cannot influence. ${ }^{9}$ As such, we construct measures of these personality traits or non-cognitive skills (namely, locus of control, work ethic, and self-esteem)

\footnotetext{
${ }^{8}$ The number of observation varies in the different models, depending on the number of missing values in each outcome considered.

${ }^{9}$ People who believe that they have a significant influence on their life outcomes are characterized as having an internal locus of control.
} 
following the literature by using factor analysis to summarize the response to the questions available in Next Steps (Mendolia and Walker, 20I4 and 20I5). These are included in the vector of independent variables in the econometric specifications below (see the Online Appendix for further details).

Our outcome measures all pertain to risky health behaviors: whether the adolescent engaged in sexual intercourse; having ever tried alcohol; drinking alcohol at least once a month; having tried cigarettes; having tried cannabis; and having ever been involved in a fight. We focus on early initiation and restrict the sample to behaviors observed at ages I4-I7. As suspected, simple correlations indicate that adolescents who are more religious or who have a high work ethic and high religiosity are less likely to engage in many of the risky health behaviors.

Our independent variable of interest is the degree of religiosity across individuals. Youths report their religious group and they rate the importance of religion in their way of life on a scale from I (not important at all) to 4 (very important). This is our measure of intrinsic religiosity. Christianity is the most common religious affiliation in the estimation sample (almost $48 \%$ ), followed by Islam (I2\%). The proportion of youths who declare that religion is very important in their life is around $20 \%$. Over $40 \%$ declare no religious affiliation or say that religion is not important at all in their lives. Among those who say that religion is very important in their lives, the majority are Muslim (53\%), followed by Christians (30\%).

Next Steps includes two questions on self-esteem asked at Waves 2 and 4. These questions are distinct from those evaluating individuals' mental health through the General Health Questionnaire. We follow the literature (see, e.g., Ermisch et al. (2001)) and construct an indicator of low self-esteem, along with work ethic and locus of control. ${ }^{10} \mathrm{We}$ classify youths as

\footnotetext{
${ }^{10}$ Next Steps does not include "Big Five personality traits" questions (openness to experience, conscientiousness, extraversion, agreeableness, and neuroticism) commonly used in similar analyzes (see Almlund et al. 2011).
} 
having low self-esteem if they have placed themselves in the most distressed category for one of the two questions at least once across the two waves (Mendolia and Walker 2014, 2015). Around $24 \%$ of the children in the sample are classified as having low self-esteem using this definition.

Next Steps also includes four questions on working attitudes with respect to school work asked at Wave 2, and we use factor analysis to define an index of work ethic (Mendolia and Walker 2014, 2015). Individuals are defined as having high work ethic if they are in the top quartile of the distribution of this index (Schurer 2017). Locus of control refers to an individual's perception of her ability to determine life events. Individuals with an external locus of control believe that their life is mostly determined by events outside their control. We measure locus of control using responses to six questions and use factor analysis to create indices of internal and external loci of control. Youths are coded as having external locus of control if they have a score in the top quartile of the distribution of the external index. All questions on personality traits in Next Steps are reported in the Online Appendix.

Table I provides descriptive statistics for each of the relevant control variables used in the analysis, for the sample pooled across all waves and treated as a cross-section. The first column relates to all observations, while subsequent ones relate to subsets defined by various non-cognitive skills and degrees of religiosity (e.g., the sample includes 9,544 individuals with external LOC and so on). The sample size in this table is different from the ones from Tables 2 to 5 because individuals with missing outcomes observations, missing religiosity or missing school identifiers (depending on models) have to be dropped in the estimation. However, we provide descriptive statistics for the general sample, rather than for different outcome samples (i.e. the number of missing observations varies for each outcome). 
Children who say that religion is very important in their daily lives, tend to have a lower Key Stage 2 (KS2) scores (test scores at age Io), live in more deprived neighbourhoods, have more siblings, are much less likely to have a well-educated mother, but more likely to live in a high-income household.

Figure I shows the distribution of religiosity in the estimation sample. In particular, we present percentages of youths in the survey who report that religion is not important at all, not very important, fairly important and very important in each wave. Over $40 \%$ of youths in the sample report no religion /religion is not important at all. The proportions declaring not very, fairly, and very important are close to $20 \%$ for each category. In the Appendix (Figure AI and A2), we report the degree of religiosity by age and by religious affiliation. Figure AI shows that there is very limited variation in religiosity with age, and Figure A2 shows that Muslim youths exhibit the highest degree of religiosity, while Christians show the lowest level of religiosity.

Figure 2 reports outcomes by religiosity. Not surprisingly, there is a strong negative association between risky behaviors and high levels of religiosity, compared to average. For example, the average proportion of youths aged I4-I7 who have had sexual intercourse is around $25 \%$, but this percentage drastically declines to $10 \%$ for youths with high levels of religiosity, and increases to $30 \%$ among youths with no religion (or religion not important at all). A similar pattern is observed for all risky behaviors.

Similarly, Figure 3 presents outcomes by personality traits. Individuals with high work ethic are much less likely to engage in each risky behavior.

Lastly, Figure 4 presents the proportion on individuals with different personality traits, in the whole sample, and by religiosity. For example, there is about $22 \%$ of individuals with high work ethic in the sample, but this proportion is higher among the individuals who show 
high religiosity (around 35\%). However, there is no particular overall pattern for low self-esteem and external locus of control.

A possible limitation of our study is that individuals may not provide sincere answers to the religiosity questions. This is relevant here because respondents are interviewed face-toface (albeit computer-assisted), and there may be a social expectation to respond in a certain way. In this case, however, it is not altogether clear that the respondents would be inclined to over- or underestimate the importance of religion in their lives. Many developed countries are effectively secularized and people may prefer not to profess a religion. This is essentially an issue of measurement error, and there is an expectation that this will underestimate the impact of this variable. While these are self-reported answers to a computer assisted interview where the parent can be present, the differences in these distributions of religiosity responses are not very sensitive to whether the parent is present or not.

Indeed, the relevant literature that has investigated religiosity (see, e.g., Fletcher and Kumar, 20I4 and Fruehwirth et al., forthcoming), shows that measures of self-reported (or intrinsic) religiosity are less likely to be socially influenced or sanctioned than extrinsic measures, such as church attendance and prayer. Furthermore, previous studies have suggested that it is important to separately consider believing (measured through prayer and religious importance) from other measures of religiosity. The rationale for this is that the way in which religiosity is measured has been shown to affect individual outcomes differently (Iyer, 20I6). Finally, we include a variety of control variables in our analysis, such as parental characteristics, religious affiliation, and individual personality traits, as these may correlate with the likelihood of providing truthful answers. 
TABLE 1 MEANS (STD DEVS) OF INDEPENDENT VARIABLES FOR SUB-GROUPS OF ESTIMATION SAMPLE, BY PERSONALITY TRAITS AND RELIGIOSITY

\begin{tabular}{|c|c|c|c|c|c|c|c|c|c|}
\hline & $\begin{array}{l}\text { Whole } \\
\text { sample }\end{array}$ & $\begin{array}{l}\text { External } \\
\text { LOC }\end{array}$ & $\begin{array}{c}\text { Internal } \\
\text { LOC }\end{array}$ & $\begin{array}{l}\text { Low self- } \\
\text { esteem }\end{array}$ & $\begin{array}{l}\text { High self- } \\
\text { esteem }\end{array}$ & $\begin{array}{l}\text { High work } \\
\text { ethic }\end{array}$ & $\begin{array}{l}\text { Low work } \\
\text { ethic }\end{array}$ & $\begin{array}{l}\text { Religion very } \\
\text { important }\end{array}$ & $\begin{array}{l}\text { No religion or not } \\
\text { at all important }\end{array}$ \\
\hline \multirow[t]{2}{*}{ Average KS2 score } & 27.0 & 25.6 & 27.3 & 26.9 & 27.1 & 27.4 & 27.1 & 25.9 & 27.7 \\
\hline & $(4.0)$ & $(4.2)$ & $(3.9)$ & $(4.1)$ & $(4.0)$ & $(3.8)$ & $(3.7)$ & $(4.5)$ & (3.6) \\
\hline \multirow[t]{2}{*}{ Average IMD score } & 25.3 & 28.3 & 26.8 & 25.0 & 25.4 & 27.2 & 23.8 & 35.6 & 20.6 \\
\hline & $(17.7)$ & $(18.2)$ & $(17.8)$ & $(17.4)$ & $(17.8)$ & $(18.4)$ & $(17.4)$ & $(17.7)$ & $(15.9)$ \\
\hline \multirow[t]{2}{*}{ Children in the family } & 2.1 & 2.2 & 2.1 & 2.1 & 2.1 & 2.2 & 2.9 & 2.6 & 1.9 \\
\hline & $(1.1)$ & $(1.2)$ & $(1.1)$ & $(1.1)$ & $(1.1)$ & $(1.1)$ & $(1.1)$ & $(1.4)$ & $(0.9)$ \\
\hline \multirow[t]{2}{*}{ Mother's age } & 42.97 & 42.7 & 43.3 & 43.2 & 42.9 & 42.9 & 43.1 & 43.0 & 43.3 \\
\hline & $(5.60)$ & $(5.7)$ & $(5.4)$ & $(5.6)$ & $(5.6)$ & $(5.5)$ & $(5.6)$ & $(6.0)$ & $(5.2)$ \\
\hline Mother has a degree $(\%)$ & 10.3 & 7.9 & 10.5 & 11.7 & 9.9 & 10.3 & 11.3 & 7.3 & 10.4 \\
\hline Mother has other HE (\%) & 11.8 & 9.3 & 11.1 & 12.5 & 11.6 & 10.9 & 11.1 & 7.8 & 14.4 \\
\hline Mother senior high school (\%) & 12.0 & 11.7 & 12.7 & 11.7 & 12.1 & 11.2 & 12.9 & 6.1 & 14.4 \\
\hline Mother high school grades a-c (\%) & 25.8 & 22.9 & 25.4 & 24.9 & 26.1 & 23.9 & 27.1 & 13.6 & 31.4 \\
\hline Mother qual. level $\leq 1(\%)$ & 8.1 & 9.4 & 7.6 & 7.9 & 8.2 & 7.3 & 9.4 & 3.7 & 9.6 \\
\hline Mother has other qual. (\%) & 2.5 & 2.9 & 3.3 & 2.9 & 2.4 & 2.7 & 2.5 & 3.0 & 2.4 \\
\hline Mother has no education (\%) & 25.1 & 31.7 & 26.3 & 24.4 & 26.4 & 30.0 & 21.8 & 55.5 & 13.1 \\
\hline Single mother $(\%)$ & 23.3 & 26.1 & 22.4 & 25.1 & 25.3 & 19.3 & 25.7 & 16.0 & 21.9 \\
\hline Mother age $\leq 20$ at birth $(\%)$ & 6.1 & 7.6 & 7.5 & 6.2 & 6.2 & 6.1 & 5.7 & 6.9 & 4.8 \\
\hline Male $(\%)$ & 50.6 & 53.3 & 53.3 & 40.0 & 54.0 & 46.8 & 53.5 & 48.1 & 48.6 \\
\hline Black $(\%)$ & 6.6 & 6.7 & 8.6 & 6.2 & 6.7 & 9.9 & 3.9 & 16.0 & 3.1 \\
\hline Asian (\%) & 17.1 & 19.7 & 21.4 & 16.9 & 17 & 26.8 & 11.0 & 60.1 & 3.1 \\
\hline Mixed $(\%)$ & 7.2 & 7.6 & 7.5 & 8.3 & 6.8 & 7.1 & 7.0 & 8.7 & 5.2 \\
\hline Mother unemployed (\%) & 1.6 & 1.8 & 1.9 & 1.9 & 1.5 & 1.7 & 1.6 & 1.7 & 1.3 \\
\hline Mother out of labour force $(\%)$ & 30.8 & 36.4 & 32.6 & 31.0 & 30.7 & 34.9 & 27.6 & 60.5 & 19.5 \\
\hline Takes private lessons $(\%)$ & 11.4 & 9.5 & 12.0 & 12.3 & 11.1 & 14.6 & 9.9 & 14.2 & 10.8 \\
\hline English is $1^{\text {st }}$ language (\%) & 94.0 & 93.5 & 95.8 & 94.5 & 93.0 & 92.2 & 97.0 & 78.2 & 98.9 \\
\hline Income $<£ 11,400(\%)$ & 22.2 & 16.3 & 21.4 & 22.9 & 19.0 & 21.2 & 24.5 & 8.5 & 28.5 \\
\hline$£ 11,400<$ Income $<£ 31,200(\%)$ & 33.7 & 35.9 & 33.9 & 33.9 & 33.6 & 34.5 & 33.6 & 31.0 & 35.3 \\
\hline Income $>£ 31,200(\%)$ & 19.2 & 22.3 & 19.9 & 19.7 & 22.2 & 19.6 & 19.5 & 22.5 & 15.8 \\
\hline $\mathrm{N}$ & 53,549 & 9,544 & 6,636 & 13,625 & 39,924 & 9,744 & 11,917 & 9,990 & 10,852 \\
\hline
\end{tabular}

Note: Standard deviations in brackets. KS2 is a national test score at age 10. IMD is an index of neighborhood deprivation. Income is in 2004 prices. Level 1 qualifications include: GCSE (at age 16) passing grades A, B, C; level 1 certificate; level 1 award; level 1 national qualifications (all lower level qualifications than junior high school). The sample size includes all individuals in waves $1-4$ with no missing religiosity information. Different columns include sub-gro
sizes in Tables 1 to 5 in the main text are different as individuals with missing information are dropped across various models. N represents number of observations (person $\times$ wave). 


\section{FIGURE 1 INTRINSIC RELIGIOSITY IN THE ESTIMATION SAMPLE (PERCENT)}

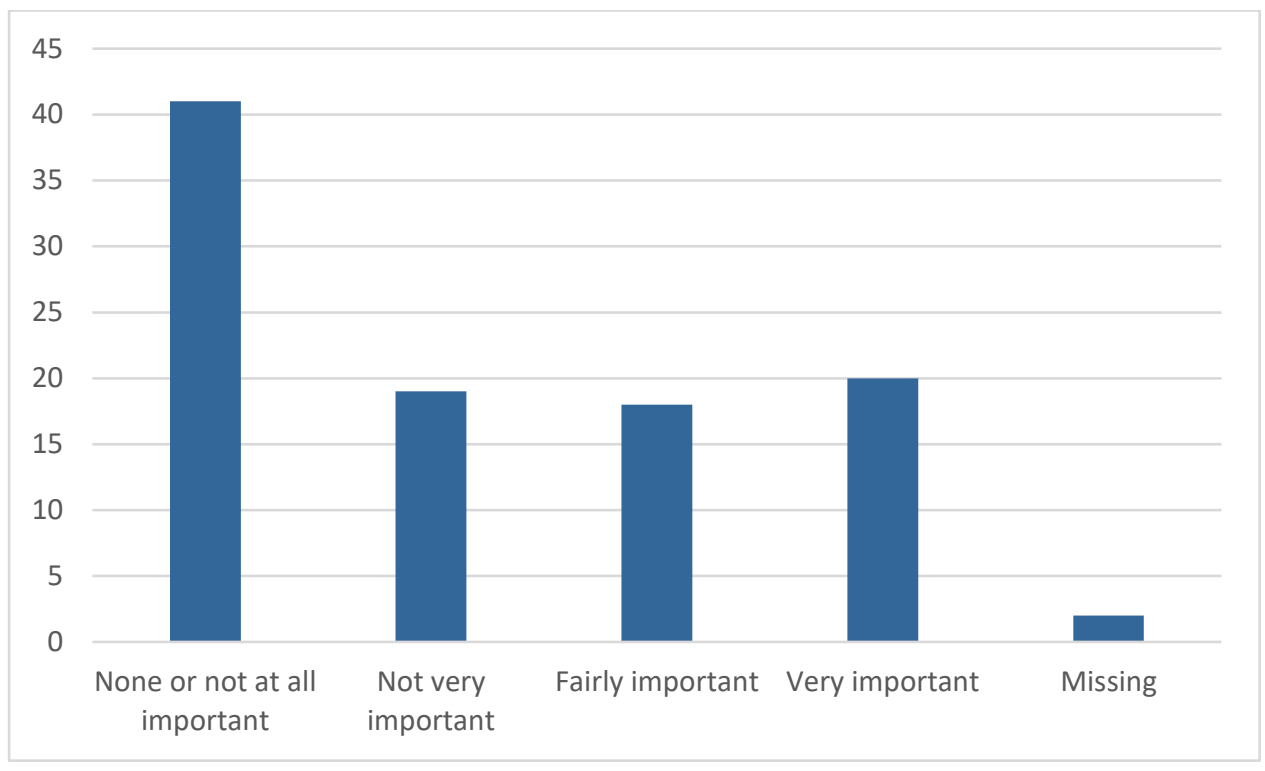

Note: Sample size $=53,549$ observations

\section{FIGURE 2 OUTCOMES BY RELIGIOSITY (PERCENT)}

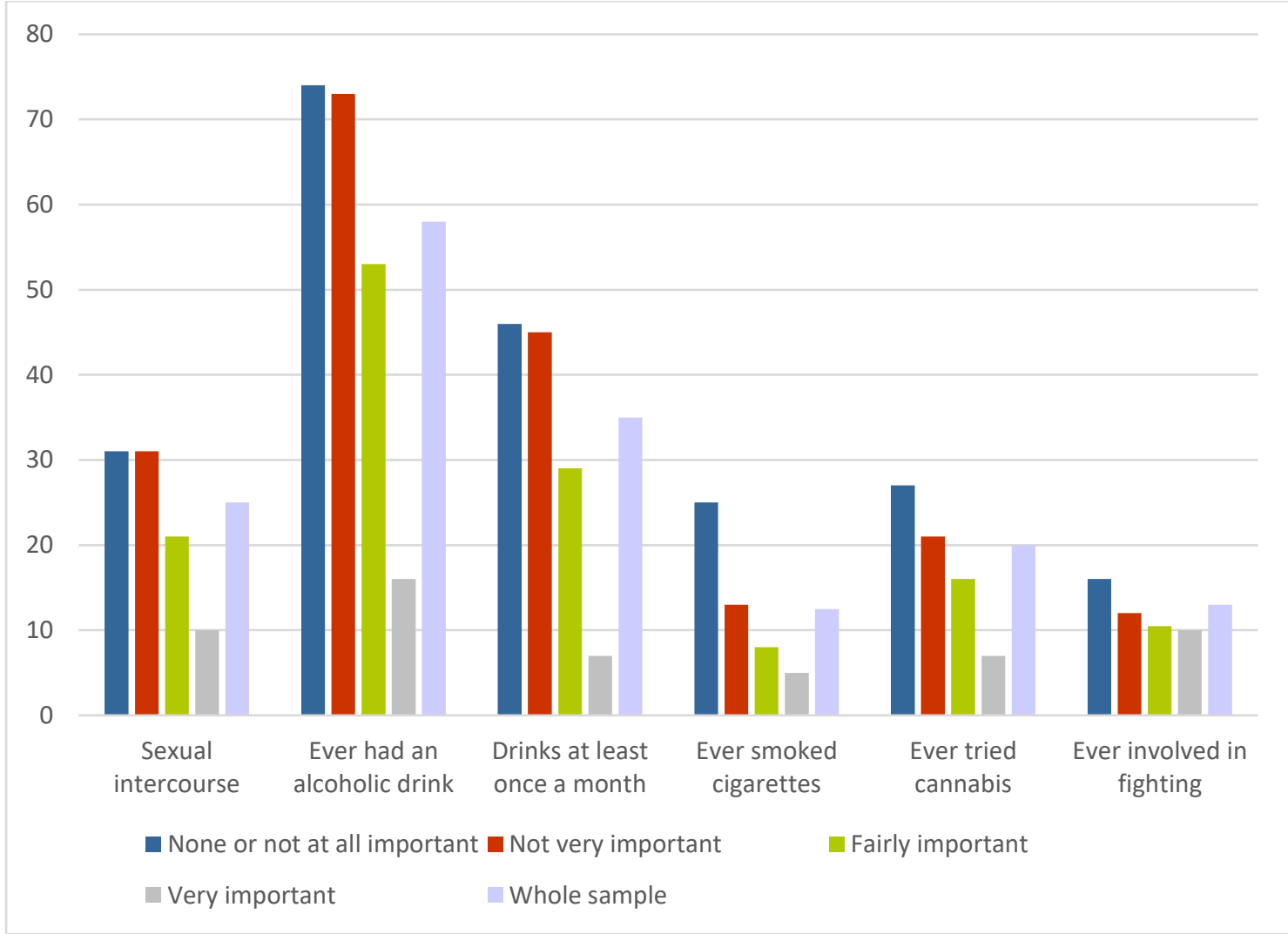

Note: Sample size $=53,549$ observations (Percentages are calculated excluding individuals with missing observations on each outcome). 


\section{FIGURE 3 OUTCOMES BY PERSONALITY TRAITS (PERCENT)}

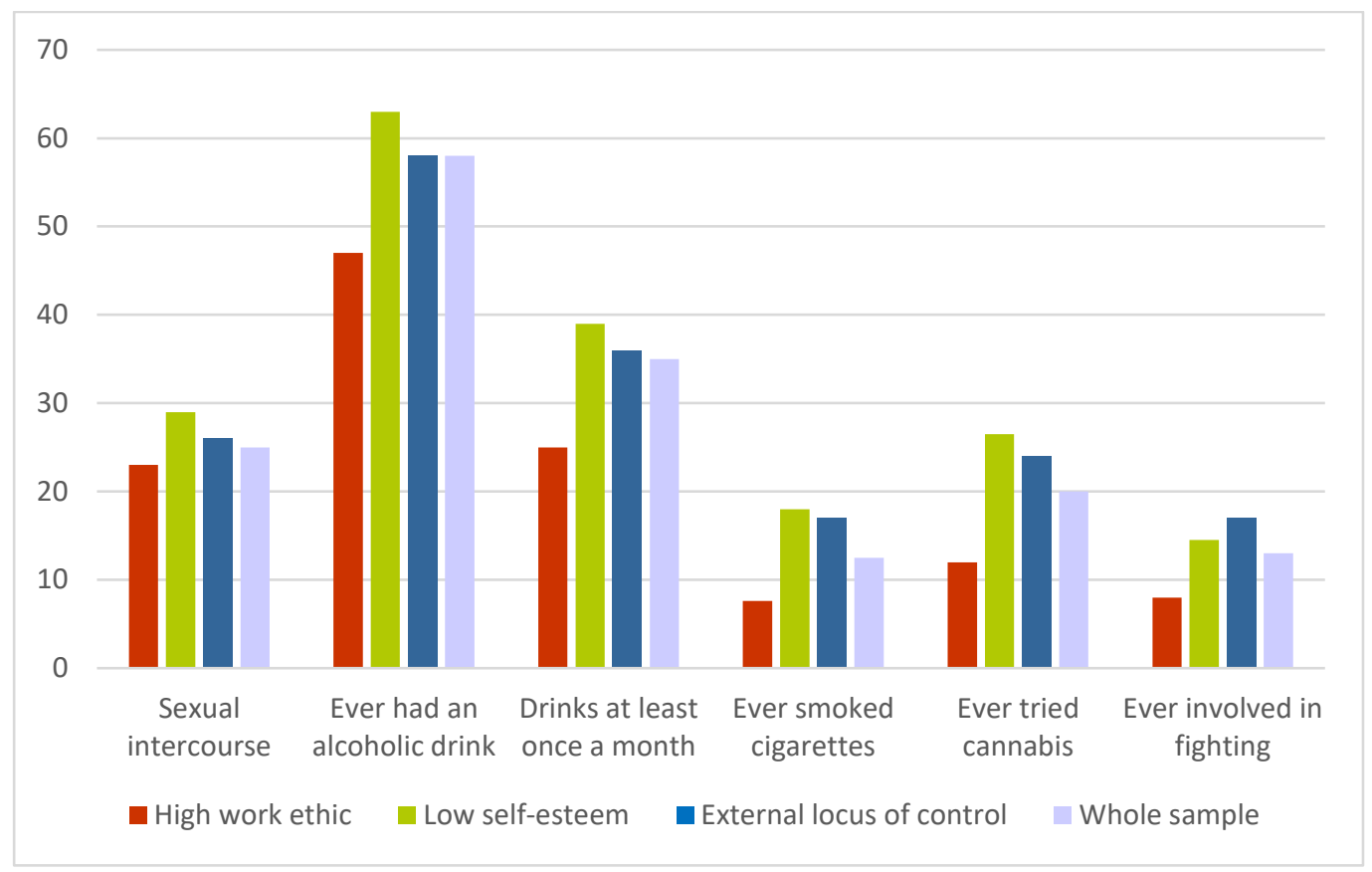

Note: Sample size $=53,549$ observations (Percentages are calculated excluding individuals with missing observations on each outcome).

\section{FIGURE 4 PERSONALITY TRAITS BY RELIGIOSITY (IN PERCENT)}

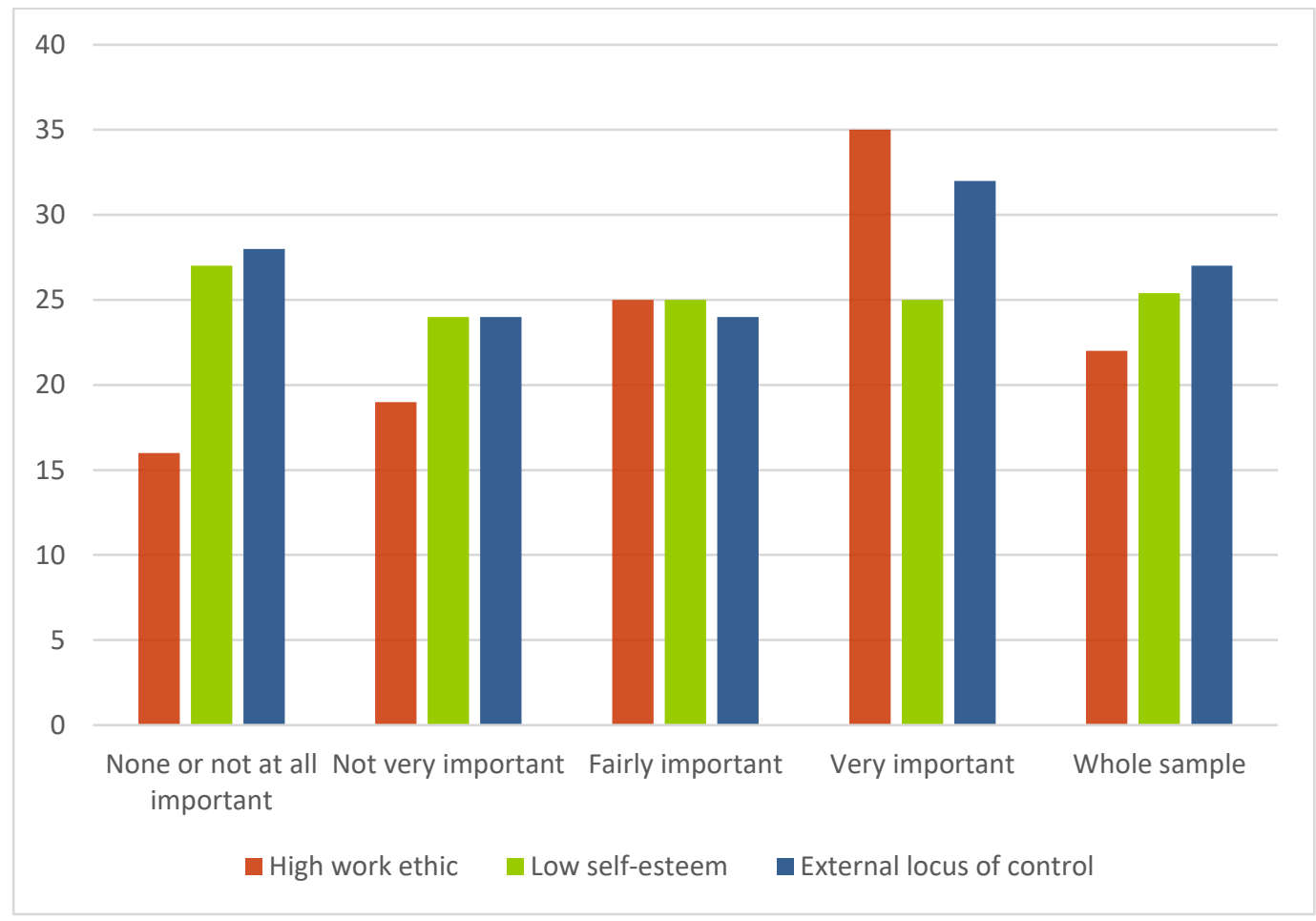

Note: Sample size $=53,549$ observations (Percentages are calculated excluding individuals with missing observations on each personality trait). 


\section{Empirical Model}

We begin by estimating an OLS model to control for observable confounders:

$$
h_{i j t}=\alpha+\beta r_{i j t}+\boldsymbol{\gamma}^{\prime} \mathbf{p}_{i j t}+\boldsymbol{\delta}^{\prime} \mathbf{x}_{i j t}+\varepsilon_{i j t}
$$

where $h_{i j t}$ represents a risky health behavior for individual $i$ in school $j$ at time $t ; r_{i j t}$ is an individual's reported intrinsic religiosity; $\mathbf{p}_{i j t}$ is a vector of psychological traits; $\mathbf{x}_{i j t}$ is a vector of child and family characteristics, including religious denomination, for an individual; and $\varepsilon_{i j t}$ is the unobservable determinant of the health behavior, which we assume can be decomposed into a school fixed effect and an idiosyncratic component.

The vector of covariates includes the individual's age (binary variables), ethnicity, results in test scores at age Io, maternal education and employment, whether the child lives with a single mother, maternal age and age at birth, whether English is the first language in the family, whether the child receives private lessons, the presence of older siblings, and the index of multiple deprivation (IMD) score. ${ }^{11}$ We extend the model to include household annual income recorded in 2004 prices at Wave I.

In the presence of unobserved confounders, OLS is an inconsistent estimator of the population-level parameter of interest, which is the association between religiosity and personality traits and risky health behaviors. However, this is a rich dataset, and by including an extended list of control variables, we can make some progress towards reducing the bias caused by unobserved heterogeneity. That said, we caution against inferring causality from the estimated models that do not contain time-invariant fixed effects, but we do emphasize instead the robustness of the statistically significant relationships that arise.

\footnotetext{
11 The IMD is a government-produced statistic that indicates the relative deprivation of small areas in England. The index is based on a variety of socioeconomic characteristics, such as income, employment, education, health, and so on, associated with a local area.
} 
We also include school fixed effects in the estimation in order to take into consideration the fact that individuals attending the same school are likely to have common unobserved characteristics that do not vary over time that may influence their propensity to engage in risky behaviors. These typically include indicators of socioeconomic status not otherwise captured by the control variables in the vector $\mathbf{x}_{i j t}$, environmental factors, as well as school-specific characteristics such as religious denomination, teacher quality, and disciplinary policies. ${ }^{12}$

OLS estimates could be biased because of unobserved characteristics that simultaneously affect religiosity and the propensity to engage in risky health behaviors. However, Next Steps is a longitudinal dataset, and questions concerning intrinsic religiosity and our outcome variables of interest are asked repeatedly. This allows us to leverage "within" (i.e., person-specific) variation in the levels of religiosity between individuals and estimate an individual fixed-effects model that can be written as:

$$
h_{i j t}=\alpha+\beta r_{i j t}+\boldsymbol{\gamma}^{\prime} \mathbf{p}_{i j t}+\boldsymbol{\delta}^{\prime} \mathbf{x}_{i j t}+\mu_{i}++\varepsilon_{i j t}
$$

where $\mu_{i}$ represents a set of time-invariant individual characteristics.

Unfortunately, fixed effects estimation is not a panacea. In the "within" model with individual fixed effects, the causal interpretation of $\beta$ relies on the assumption that the timedependent error term $\varepsilon_{i j t}$ is independent of changes in religiosity and risky behaviors, conditional on the regressors, $\mathbf{p}_{i j t}$, and $\mathbf{x}_{i j t}$, and the individual fixed effect. This assumption fails if there are unobserved random shocks that affect both risky behaviors and religiosity. For this reason, we control for a wide set of characteristics to test the sensitivity of our main findings, and we use inverse probability weighted regression adjustment (IPWRA) treatment effects estimation to show the stability of the main results using different estimation techniques.

\footnotetext{
12 The majority of students in the sample attend government schools with no religious affiliation, but the sample also includes a small proportion of Catholic schools (around 7\%) and Church of England schools (around 5\%). Individuals in the sample come from over 650 schools, and there are, on average, 32 observations from each.
} 
In particular, we examine the role of multiple personality traits and different combinations of personality traits and religiosity using IPWRA treatment effects estimation based on the implementation in Cattaneo et al. (20I3). ${ }^{13}$ Specifically, the probability of "treatment" (in this context, having a certain level of religiosity, or a combination of religiosity and personality traits) is estimated using a multinomial logit specification. The inverse of these predicted probabilities are used as weights in a second-stage regression (Wooldridge, 2007; Wooldridge, 20I0; and Imbens and Wooldridge, 2009).

The IPWRA estimator has the "double robustness property" (Wooldridge, 2007 and 20I0) in that only one of the two equations in the model must be correctly specified to consistently estimate the parameters of interest. In practice, estimates in the second stage (the risky behavior equation) are robust to misspecification of the first stage (the multinomial logit model of treatment propensities) provided that the second stage is correctly specified. Similarly, estimates from the first stage are robust to the second step, provided the weighting is correctly specified.

Nonetheless, like OLS, estimation by IPWRA relies on the conditional-independence assumption in order to identify the effect of religiosity on health risky behaviors. If we have enough information on the observable differences between youths with and without the treatments, we can heavily weight treated observations that have similar observables to untreated individuals and obtain unbiased estimates of the causal relationship between religiosity and health risky behaviors (Mendolia and Walker, 20I5). Technically, the estimator weights similar observations across treatment groups highly, relying less on the functionalform assumption embedded in the regression step. Indeed, by putting disproportionate weight on control observations that are most like treated observations, IPWRA reduces the reliance on functional form that OLS imposes.

\footnotetext{
${ }^{13}$ These estimates are calculated using the teffects ipwra routine in Stata (StataCorp, 20I7).
} 


\section{Results}

The estimation results from the model including school fixed effects are presented in Table 2, followed by results, which account for individual-level fixed effects in Table 2 . We then present results from the estimation of the relationship between multiple traits and various levels of religiosity (on one side) and the propensity to engage in risky health behaviors (on the other side) in Tables 3 and $4^{14}$. Standard errors are clustered at the individual level throughout to account for individual-specific correlation across the four waves of the longitudinal dataset. The results presented are based on unweighted regressions; the use of survey weights produced similar estimates.

The strongest associations are found when using school-level fixed effects (Table 2). In particular, individuals who declare that religion is fairly important or very important in their lives are significantly less likely to engage in sexual activity at ages I4-I7 ( -7 p.p for fairly important and -I4 p.p. for very important compared to a mean of $25 \%$ ); to have tried alcohol ( -9 p.p. and $-\mathrm{I} 9$ p.p. compared to a mean of $63 \%)$; or being regular drinkers $(-8$ p.p. and $-\mathrm{I} 2$ pp. with a mean of $38 \%)$; to have tried cannabis ( -7 p.p. and -II p.p. with a mean of $19 \%)$; or cigarette smoking ( -7 p.p. and -9 p.p. with a mean of $13 \%$ ); and to having ever been involved in a fight $(-6$ p.p. and -9 p.p. with a mean of $13 \%) .{ }^{15}$ The reference category in all cases are adolescents who do either do not profess any religion or say that religion is not important at all in their lives. Appendix Table A2 presents the results analysing the associations between all the other independent variables and risky health behaviors.

\footnotetext{
${ }^{14}$ See Mendolia and Walker (20I4) for an analysis of the impact of personality traits on health risky behaviors. This previous study shows that individuals with external locus of control, low self-esteem or with low levels of work ethics seem more likely in engage in risky health behaviors

${ }^{15}$ For brevity, the estimated impacts are rounded off to the nearest integer when reporting outside the tables.
} 
Table 3 presents results from the model with individual fixed effects. This model relies on youth-specific variation across waves of religiosity and risky behaviors to identify the effects. As mentioned previously, the credibility of the estimates using the within variation turns on whether time-varying characteristics matter in determining behavioral health outcomes and religiosity. In Table AI in the Appendix, we report the within standard deviation in the variable which measures the importance of religion in the adolescent's life $(0.325$, which is likely to be large enough to allow reliable FE estimates to be obtained). We also report a transition matrix, showing changes in individuals' religiosity between time t-I and t.

The results in Table 3 are, unsurprisingly, smaller in magnitude than those in Table 2, and some coefficients lose their statistical significance. This could be due to higher measurement error in the fixed effects regression or to the fact that we now control for individual time-invariant characteristics, which could affect religiosity and risky behaviors. However, these results are consistent with the narrative that increased intrinsic religiosity is associated with less risky health behavior. In particular, high intrinsic religiosity remains a statistically significant determinant of the reduced likelihood in ever having sexual intercourse (-2 p.p.), ever having drunk alcohol (-3 to -5 p.p.), ever having smoked (-2 p.p.), and ever having been involved in a fight (-2.5 p.p.). The decrease in statistical significance of these results is likely due to the limited within-individual variation in the level of religiosity. The statistically significant relationship between religiosity and cannabis initiation in OLS is entirely missing in the individual fixed-effects approach. The list of included covariates is smaller in this model, as only time-varying individual characteristics can be included in a model with individual fixed effects.

Together with Table 2, this set of results indicates that unobserved, individual-level, time-invariant heterogeneity matters substantially for the probability of engaging in risky health behaviors. This is perhaps not surprising given the strong selection effects that pervade 
religious choice, the intensity of practice, and the strength of one's beliefs. That said, to the extent that the estimation approach is able to take this into account, intrinsic religiosity evidently has an independent impact on the propensity to have early initiation of sexual intercourse, alcohol, smoking, and physical violence. 
TABLE 2 - RELIGIOSITY AND BEHAVIORAL HEALTH OUTCOMES (LEAST SQUARES WITH SCHOOL FIXED EFFECTS)

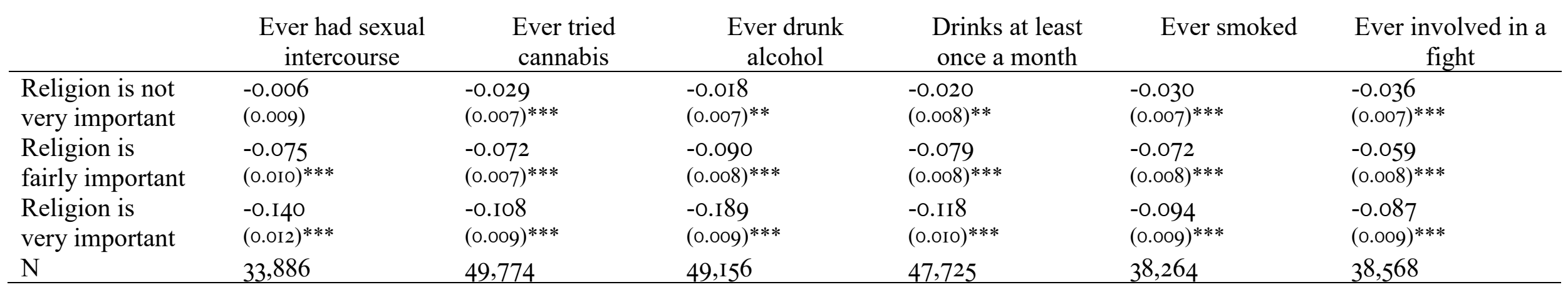

Omitted group: no religion or religion is not important at all. Included covariates: Individual's gender, age, religious affiliation; , KS2 test score, high work ethics, low self-esteem, external locus of control, ethnicity, English as first language, takes private lessons, mother's education, mother's age single mother, mother's employment status; mother younger than 20 at birth; IMD score; number of children in the family presence of older siblings; income groups in wave I (annual income $>£ 3 \mathrm{I}, 200$; between $£$ II, 400 and $£_{31}, 200$; and $<£$ I, 400 omitted). * indicates significant at IO $\%$ level, ** at $5 \%$ and $* * *$ I $\%$. N represents number of observations (person $\times$ wave).

TABLE 3 - RELIGIOSITY AND BEHAVIORAL HEALTH OUTCOMES (LEAST SQUARES WITH INDIVIDUAL FIXED EFFECTS)

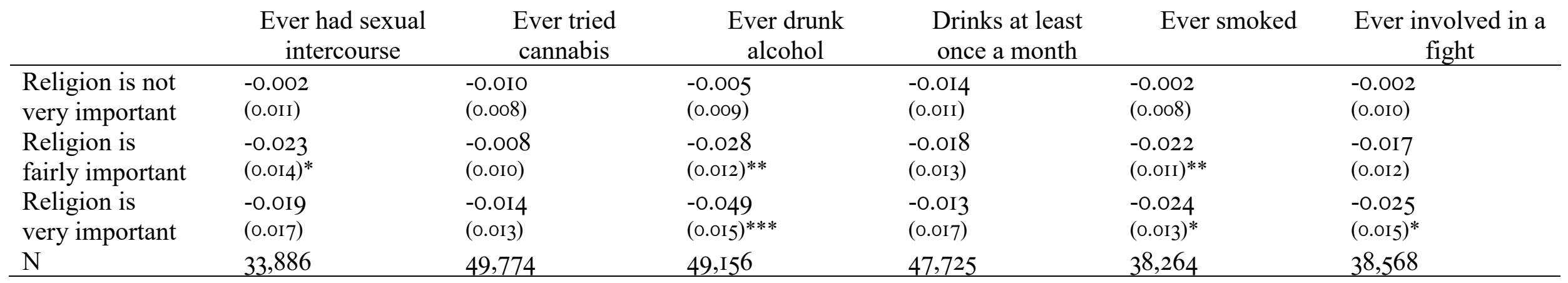

Omitted group: no religion or religion is not important at all. Included covariates: Religious affiliation; mother's education, single mother, age binary variables, mother's employment status; number of children in the family. $*$ indicates significant at $10 \%$ level, $* *$ at $5 \%$ and $* * * 1 \%$. . N represents number of observations (person $\times$ wave). 
Two other results, available on request, are worth noting: the lack of heterogeneity by gender and the heterogeneity across different religious denominations. The estimated coefficients are similar in size and significance for boys and girls with only a few exceptions, particularly on the association between religiosity on smoking. Religiosity seems to be relevant for females only in this regard. In terms of differences across religious affiliation, we find that Muslim, Hindu, and Sikh boys and girls are less likely to engage in risky health behaviors, and particularly in early sexual activity and underage drinking.

In addition, we ran sensitivity tests including additional covariates in the model, such as maternal disability and individual's health status. In the face of intimations of mortality, one might expect the afflicted to grasp at a supernatural who can lend succor. We also tested whether an indicator for attending a religious school matters. The results do not change enough to warrant comment and are available on request. Lastly, we estimate two additional models including lags and leads of religiosity. Results are reported in the Appendix (Table A3 and A4) and show that leads of religiosity never have any impact on risky behaviors, while lags significantly affect them.

Notably, all our results are consistent with previous findings using US data (Fletcher and Kumar, 20I4; Gruber, 2005 and Mellor and Freeborn, 20II). The most directly comparable analyses to our own are the work by Sinha et al. (2007) and the study by Fletcher and Kumar (20I4). Our results are consistent with this existing literature, but substantially complement this evidence by explicitly taking into account individual unobserved heterogeneity and the role of multiple combinations of religiosity and personality traits.

Tables 4 and 5 present results from the treatment effects with IPWRA estimator. The number of observations in these tables is slightly lower than the one from the previous tables since individuals with low propensity scores are automatically eliminated from the sample by the estimation software to guarantee model convergence. 
In Table 4, we use IPWRA treatment effects estimation to explore the separate role of different levels of religiosity (controlling for personality traits and other observables, similarly to the OLS model with school FE, estimated in Table I). The results indicate that individuals with high religiosity are substantially less likely to engage in all risky behaviors. The estimated coefficients of religion being very important are nontrivial and statistically significant: -7 p.p for having have been involved in a fight and smoking, -I5 p.p. for regularly drinking alcohol, and -20 p.p. for engaging in early sexual activity.

In Table 5, we use IPWRA treatment effects estimation to analyse different combinations of work ethics, self-esteem and intrinsic religiosity. High religiosity is defined here as an individual who declares that religion is fairly or very important for him/her, high work ethic is defined as individuals in the top two quartiles of the work ethic index, and high self-esteem is defined as the complement of our indicator for low self-esteem. ${ }^{16}$ The omitted group is children with low self-esteem, low work-ethic, and low religiosity. We think of this as the riskiest combination of characteristics, and any departure from this would imply less risky behavior-that is, our prior is that all coefficients in Table 4 should be negative. Remarkably, all 42 parameters satisfy this condition, and 4I are statistically significant.

Comparing row I with 2, 4 with 5 and 6 with 7, it is clear that high religiosity is highly protective for all risk behaviours, except for fighting where the reduction is small (apart from the first case where the reduction is large). When we analyze the combination of high work ethic, high self-esteem, and high intrinsic religiosity, we find that individuals who have the three positive traits are best protected in the case of all six outcome behaviors. The combination of high religiosity and one of the positive traits (high self-esteem or high work ethic) is also quite protective, with estimates from $-\mathrm{I} 3$ to -25 p.p. For every combination of personality traits,

\footnotetext{
${ }^{16}$ We simplify the definitions of high/low religiosity in order to achieve sensible cell sizes, which allow the model to converge. We do not consider external locus of control in these combinations, as the effect of this trait decreases once we control for religiosity.
} 
switching from low to high religiosity generates a large protective effect. These results suggest that religiosity may play a substantial role in protecting adolescents, and possibly an even stronger role than other important traits, such as self-esteem or work ethic. 


\begin{tabular}{|c|c|c|c|c|c|c|}
\hline & $\begin{array}{l}\text { Had sexual } \\
\text { intercourse }\end{array}$ & $\begin{array}{l}\text { Ever tried } \\
\text { cannabis }\end{array}$ & $\begin{array}{l}\text { Ever drunk } \\
\text { alcohol }\end{array}$ & $\begin{array}{l}\text { Drinks at least } \\
\text { once a month }\end{array}$ & Ever smoked & $\begin{array}{c}\text { Ever involved in } \\
\text { a fight }\end{array}$ \\
\hline Religion is not very important & $\begin{array}{c}-0.0196 \\
(0.013)\end{array}$ & $\begin{array}{l}-0.0169 \\
(0.008)^{*}\end{array}$ & $\begin{array}{l}-0.019 \\
(0.014)\end{array}$ & $\begin{array}{c}-0.0196 \\
(0.013)\end{array}$ & $\begin{array}{l}-0.0202 \\
(0.010)^{*}\end{array}$ & $\begin{array}{l}-0.0205 \\
(0.014)\end{array}$ \\
\hline Religion fairly important & $\begin{array}{c}-0.084 \\
(0.012)^{* * *}\end{array}$ & $\begin{array}{c}-0.062 \\
(0.007)^{* * *}\end{array}$ & $\begin{array}{c}-0.1 \mathrm{I} 6 \\
(0.012)^{* * *}\end{array}$ & $\begin{array}{l}-0.095 \\
(0.011)^{* * *}\end{array}$ & $\begin{array}{c}-0.073 \\
(0.008)^{* * *}\end{array}$ & $\begin{array}{l}-0.05 \mathrm{II} \\
(0.012)^{* * *}\end{array}$ \\
\hline Religion very important & $\begin{array}{c}-0.193 \\
(0.015)^{* * *}\end{array}$ & $\begin{array}{c}-0.095 \\
(0.0099)^{* * *}\end{array}$ & $\begin{array}{c}-0.227 \\
(0.015)^{* * *}\end{array}$ & $\begin{array}{c}-0.154 \\
(0.014)^{* * *}\end{array}$ & $\begin{array}{r}-0.068 \\
(0.01 \mathrm{II})^{* * *}\end{array}$ & $\begin{array}{l}-0.073 \\
(0.014)^{* * *}\end{array}$ \\
\hline $\mathrm{N}$ & $33,43 \mathrm{I}$ & 49,720 & $49, \mathrm{IO} 2$ & 47,672 & 38,223 & 38,525 \\
\hline
\end{tabular}

Omitted group: No religion or religion is not important at all. Covariates: gender, age, religious affiliation; , KS2 test score, high work ethics, low self esteem, external locus of control, ethnicity, English as first language, takes private lessons, mother's education, mother's age single mother, mother's employment status; mother under than 20 at birth; IMD score; number of children in the family presence of older siblings; income groups

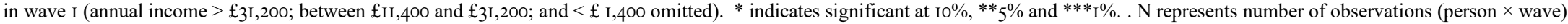

\section{TABLE 5 PERSONALITY TRAITS, RELIGIOSITY, AND BEHAVIORAL HEALTH OUTCOMES (TREATMENT EFFECTS IPWRA)}

\begin{tabular}{|c|c|c|c|c|c|c|}
\hline & $\begin{array}{l}\text { Had sexual } \\
\text { intercourse }\end{array}$ & $\begin{array}{l}\text { Ever tried } \\
\text { cannabis }\end{array}$ & $\begin{array}{l}\text { Ever drunk } \\
\text { alcohol }\end{array}$ & $\begin{array}{l}\text { Drinks at least } \\
\text { once a month }\end{array}$ & Ever smoked & $\begin{array}{l}\text { Ever involved in } \\
\text { a fight }\end{array}$ \\
\hline $\begin{array}{l}\text { I. Self-esteem=High, Work-ethic=Low, } \\
\text { Religiosity=Low }\end{array}$ & $\begin{array}{l}-0.0018 \\
(0.019)\end{array}$ & $\begin{array}{c}-0.1077 \\
(0.0156) * * *\end{array}$ & $\begin{array}{c}-0.059 \\
(0.016) * * *\end{array}$ & $\begin{array}{c}-0.062 \\
(0.016)^{* * *}\end{array}$ & $\begin{array}{c}-0.128 \\
(0.017)^{* * *}\end{array}$ & $\begin{array}{c}-0.07 \mathrm{I} 3 \\
(0.019) * * *\end{array}$ \\
\hline $\begin{array}{l}\text { 2. Self-esteem }=\text { High, Work-ethic }=\text { Low, } \\
\text { Religiosity }=\text { High }\end{array}$ & $\begin{array}{c}-0.125 \\
(0.023)^{* * *}\end{array}$ & $\begin{array}{c}-0.124 \\
(0.019)^{* * *}\end{array}$ & $\begin{array}{l}-0.160 \\
(0.018) * * *\end{array}$ & $\begin{array}{c}-0.096 \\
(0.020) * * *\end{array}$ & $\begin{array}{c}-0.100 \\
(0.021)^{* * *}\end{array}$ & $(0.02 \mathrm{I})^{* * *}$ \\
\hline $\begin{array}{l}\text { 3. Self-esteem=Low, Work-ethic }=\text { Low, } \\
\text { Religiosity=High }\end{array}$ & $\begin{array}{c}-0.127 \\
(0.018)^{* * *}\end{array}$ & $\begin{array}{c}-0.187 \\
(0.015)^{* * *}\end{array}$ & $\begin{array}{c}-0.208 \\
(0.015)^{* * *}\end{array}$ & $\begin{array}{c}-0.148 \\
(0.016) * * *\end{array}$ & $(0.016)^{* * *}$ & $\begin{array}{l}-0.137 \\
(0.018) * * *\end{array}$ \\
\hline $\begin{array}{l}\text { 4. Self-esteem }=\text { Low, Work-ethic }=\text { High, } \\
\text { Religiosity=Low }\end{array}$ & $\begin{array}{c}-0.056 \\
(0.02 \mathrm{I})^{* * *}\end{array}$ & $\begin{array}{c}-0.119 \\
(0.018) * * *\end{array}$ & $\begin{array}{c}-0.05 \mathrm{I} 6 \\
(0.019)^{* * *}\end{array}$ & $\begin{array}{c}-0.06 \mathrm{I} \\
(0.020) * * *\end{array}$ & $\begin{array}{c}-0.123 \\
(0.018)^{* * *}\end{array}$ & $\begin{array}{c}-0.104 \\
(0.023) * * *\end{array}$ \\
\hline $\begin{array}{l}\text { 5. Self-esteem=Low, Work-ethic }=\text { High, } \\
\text { Religiosity=High }\end{array}$ & $\begin{array}{c}-0.014 \mathrm{I} \\
(0.023)^{* * *}\end{array}$ & $\begin{array}{c}-0.202 \\
(0.017)^{* * *}\end{array}$ & $\begin{array}{c}-0.234 \\
(0.019)^{* * *}\end{array}$ & $\begin{array}{c}-0.187 \\
(0.019)^{* * *}\end{array}$ & $\begin{array}{c}-0.185 \\
(0.020)^{* * *}\end{array}$ & $\begin{array}{c}-0.138 \\
(0.020)^{* * *}\end{array}$ \\
\hline $\begin{array}{l}\text { 6. Self-esteem }=\text { High, Work-ethic }=\text { High, } \\
\text { Religiosity=Low }\end{array}$ & $\begin{array}{c}-0.0522 \\
(0.019)^{* * *}\end{array}$ & $\begin{array}{l}-0.1903 \\
(0.015)^{* * *}\end{array}$ & $\begin{array}{c}-0.127 \\
(0.016) * * *\end{array}$ & $\begin{array}{c}-0.134 \\
(0.016) * * *\end{array}$ & $\begin{array}{c}-0.196 \\
(0.017)^{* * *}\end{array}$ & $\begin{array}{c}-0.164 \\
(0.017) * * *\end{array}$ \\
\hline $\begin{array}{l}\text { 7. Self-esteem }=\text { High, Work-ethic }=\text { High, } \\
\text { Religiosity }=\text { High }\end{array}$ & $\begin{array}{c}-0.17 \mathrm{I} \\
(0.0 \mathrm{I} 8)^{* * *}\end{array}$ & $\begin{array}{c}-0.242 \\
(0.015)^{* * *}\end{array}$ & $\begin{array}{c}-0.127 \\
(0.015)^{* * *}\end{array}$ & $\begin{array}{c}-0.2 \mathrm{I} 8 \\
(0.0 \mathrm{I} 6)^{* * *}\end{array}$ & $\begin{array}{c}-0.248 \\
(0.0 \mathrm{I} 6)^{* * *}\end{array}$ & $\begin{array}{c}-0.175 \\
(0.018) * * *\end{array}$ \\
\hline $\mathrm{N}$ & 29,890 & $4 \mathrm{I}, 482$ & $4 \mathrm{I}, 499$ & $40,4 \mathrm{I} 7$ & $32, \mathrm{I} 86$ & 32,450 \\
\hline
\end{tabular}

Included covariates: mother's education, single mother, age, mother's employment status; IMD score, KS2 test score at age Io; ethnicity; number of children in the family; mother under than 20 at birth; presence of

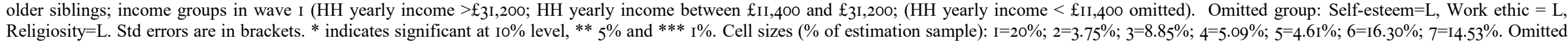
Religiosity $=\mathrm{L}$. Std errors are in brackets. * indicates significant at $\mathrm{IO} \%$
group $=8.19 \%$. N represents number of observations (person $\times$ wave). 


\section{Conclusion}

We estimate the relationship between intrinsic religiosity on the probability of engaging in a range of risky health behaviors. We use information from a longitudinal dataset of English teenagers, controlling for school- and individual-level heterogeneity. In addition, we examine the role of non-cognitive personality as well as religion. Our results indicate that intrinsic religiosity may provide important protection against engaging in risky health behaviors.

Our study focuses on the intrinsic aspect of religion and, therefore, highlights the importance of individual beliefs and personal choices rather than participation in religious activities (i.e., extrinsic religiosity). This aspect of religion is likely to have an important overlap with personality traits such as work ethic, self-esteem, and locus of control. The results suggest that religiosity has an important protective effect especially for those with the weakest psychological traits. This suggests that there is potentially a role for non-market institutions such as religion (or, more specifically, the values that are emphasized in religion) to play in managing the negative impacts that could arise out of risky health behaviors. From a policy perspective, there is a potential to focus on positive changes in personality traits (especially work ethic and self-esteem), and the development of these positive traits can be encouraged and facilitated through the collaboration between educational and religious institutions.

There are a number of channels through which religiosity can impact the likelihood to engage in risky health behaviors, including increased social interaction; support network; and higher degree of self-control (Gruber, 2005; McCullough and Willoughby, 2009; Pirutinsky, 20I4).

Identifying the causal pathways that make up the transmission mechanism through which religiosity operates on risky behaviors is beyond the scope of this paper. We, therefore, 
cannot say any more than it appears that religiosity does affect risky behaviours but we do not investigate why it does.

One may also consider extracting what is essential in religion that creates these positive behavioral outcomes, and form policies around that to extend the benefits to those adolescents who do not profess a religious belief. For instance, having religious beliefs may impact on one's "goal selection, goal pursuit, and goal management" (McCullough and Willoughby 2009), or it may influence abilities for self-monitoring and self-regulation. These skills could form part of a wider foundation for secular morality. Thus, the scope for policy instruments is not limited to those that may be wielded by the members and leaders of religious organizations. If it were possible to distil the essence of religiosity, as far as risky behavior is concerned, then there would be room for improving outcomes for children even in the absence of encouraging religion. Future research could explore possible mediators. In this context, it may be possible to find exogenous variation in attending a faith school (e.g. distance from a religious school), which might then illuminate how school choice and admission mechanisms might be changed. Indeed, exploring peer effects in religiosity might suggest how children with high religiosity should be distributed across schools. 
The authors have no conflicts of interest to declare. 


\section{References}

Almlund, M., Duckworth, A., Heckman, J. J., and Kautz, T. (20II). "Personality psychology and economics". In E. A. Hanushek, S. Machin, and L. Woessmann (Eds.), Handbook of the Economics of Education 4: I-I8I. Amsterdam: Elsevier.

Anders, J. (20I2). "Using the Longitudinal Study of Young People in England for research into Higher Education access". DoQSS Working Papers I2-I3, Department of Quantitative Social Science, Institute of Education, University College London.

Bryan, G., Choi, J., and Karlan, D. (20I8). "Randomizing Religion: The Impact of Protestant Evangelism on Economic Outcomes", NBER Working Paper No. 24278.

F. and D. Yanagizawa-Drott (2015). "Does Religion Affect Economic Growth and Happiness? Evidence from Ramadan”. Quarterly Journal of Economics 130: 615-658.

Cattaneo, M. D., D. M. Drukker, and A. D. Holland. (20I3). "Estimation of multivalued treatment effects under conditional independence". Stata Journal I3: 407-450.

Cawley, J., and Ruhm, C. (20II). "The economics of risky health behaviors", in McGuire, T., Pauly, M., and Barros, P. (eds), Handbook of Health Economics, Volume 2. (Elsevier: New York): 95-I99.

Centre for Longitudinal Studies. (20I8). Next Steps: Sweeps I-8, 2004-20I6, I4th ed., Study Number: 5545, UK Data Service.

Chiteji, N. (20I0). "Time preferences, non-cognitive skills and well-being across the life course: do non-cognitive skills encourage healthy behavior?". American Economic Review I00: 200-204.

Cobb-Clark, D., Kassenboehmer, S., and Schurer, S. (20I4). "Healthy habits: The connection between diet, exercise, and locus of control". Journal of Economic Behavior \& Organization 98: I-28.

Cobb-Clark, D, and Schurer, S. (2013). "Two economists' musings on the stability of locus of control”. Economic Journal I23: 358-40.

Conrod, P.J., O’Leavy Barret, M.A., Newton, N., Topper, L., Castellanos-Ryan, N., Mackie, C., and Girard, A. (20I3). "Effective of a Selective, Personality -Targeted Prevention Program for Adolescent Alcohol Use and Misuse". Journal of American Medical Association - Psychiatry 70: 334-342.

Department for Education. (20II). "NEXT STEPS User Guide to the Datasets: Wave I to Wave 7". Department of Education. London.

Department of Health (20II). "Abortion Statistics, England and Wales: 20I0". Department of Health: London.

Department of Health (20I6). "Health matters: harmful drinking and alcohol dependence", Public Health England. https:/www.gov.uk/government/publications/health-mattersharmful-drinking-and-alcohol-dependence/health-matters-harmful-drinking-andalcohol-dependence

Department of Health (20I7). "Towards a Smokefree generation. A Tobacco control plan for England".https://assets.publishing.service.gov.uk/government/uploads/system/uploads /attachment data/file/6302I7/Towards a Smoke free Generation. A Tobacco_Control_Plan_for_England_20I7-2022_2.pdf 
Ermisch, J., Francesconi, M., and Pevalin, D (200I). "Outcomes for children of poverty", Department for Work and Pensions. Research Report No I58. Norwich.

Fletcher, J., and Kumar, S. (20I4). "Religion and risky health behaviors among U.S. adolescents and adults". Journal of Economic Behavior and Organization I04: 123-40.

Fruehwirth Cooley, J., Iyer, S., and Zhang, A. (forthcoming). "Religion and depression in adolescence". Journal of Political Economy, forthcoming.

Gruber, J. (ed) (2000). Risky behavior among Youths: An Economic Analysis. University of Chicago Press. Chicago and London.

Gruber, J. (2005). "Religious market structure, religious participation, and outcomes: is religion good for you?". B.E. Journal of Economic Analysis and Policy 5. https://doi.org/10.1515/1538-0637.1454

Gruber, J and Hungerman, D. (2008). "The church vs the mall: What happens when religion faces increased secular competition?”. Quarterly Journal of Economics I23: 83I-862.

Hallam, S, Rhamie J, and Shaw, J. (2006). "Evaluation of the Primary Behavior and Attendance Pilot”. DfES Research Report RR7I7. DfES Publications: Nottingham.

Heckman, JJ, Stixrud J, and Urzua, S (2006). "The effects of cognitive and noncognitive abilities on labor market outcomes and social behavior". Journal of Labor Economics 24: 4II-482.

Hungerman, D.M. (20I4). "Do Religious Proscriptions Matter? Evidence from a Theory-Based Test". Journal of Human Resources 49: I053-1093.

Iannaccone, L. (1998). "Introduction to the Economics of Religion". Journal of Economic Literature 36: I465-I495.

Imbens, G.W., and Wooldridge, J.M. (2009). "Recent developments in the econometrics of program evaluation". Journal of Economic Literature 47: 5-86.

Kipping, R.R, Campbell, R.M., MacArthur, G.J., Gunnell, D. J., and Hickman, M. (20I2). "Multiple risk behavior in adolescence". Journal of Public Health 34: iI-i2.

McCullough, M.E. and Willoughby, B.L.B. (2009). "Religion, Self-Regulation, and SelfControl: Associations, Explanations, and Implications". Psychological Bulletin I35: 69-93.

Mellor, J.M., and Freeborn, B.A., (20II). "Religious participation and risky health behaviors among adolescents". Health Economics 20: I226-I240.

Mendolia, S., and Walker, I. (20I4). "The Effect of Non-Cognitive Traits on Health Behaviors in Adolescence". Health Economics 23: II46-II58.

Mendolia, S., and Walker, I. (20I5). "The effect of personality traits on subject choice and performance in high school: Evidence from an English cohort". Economics of Education Review 43: 47-65.

Mendolia, S., Paloyo, A., and Walker, I. (20I8). "Heterogeneous effects of high school peers on educational outcomes". Oxford Economic Papers 70: 613-634.

Office of National Statistics (20I4). "Conceptions in England and Wales, 20I2". ONS London.

Pirutinski, S. (20I4). "Does Religiousness Increase Self-Control and Reduce Criminal Behavior? A Longitudinal Analysis of Adolescent Offenders". Criminal Justice and Behavior 4I: I290-I307. 
Public Health England (20I3). "Numbers and rates of selected STI diagnoses in the UK, 2008I2", Online: http://www.hpa.org.uk/webc/HPAwebFile/HPAweb_C/I3I7I32033760.

Rew, L., and Wong, YJ. (2006). "A systematic review of associations among religiosity/spirituality and adolescent health attitudes and behaviors". Journal of Adolescent Health 38: 433-42.

Sabia, J., and Rees, D. (2009). "The effect of sexual abstinence on female educational attainment". Demography 46: 695-7I5.

Schurer, S. (2017). "Bouncing Back from Health Shocks: Locus of Control and Labour Supply”. Journal of Economic Behavior \& Organization I33: I-20.

Sinha, J.W., Canaan, R.A., and Galles, R.J. (2007). “Adolescent risky behaviors and religion: findings from a national study". Journal of Adolescence 30: 23I-249.

Taub, J. (2002). "Evaluation of the second step violence prevention program at a rural elementary school”. School Psychology Review 31: I86-200.

Walker, I., and Zhu, Y. (20I8). "University selectivity and the relative returns to higher education: Evidence from the UK". Labour Economics 53: 230-249.

Wooldridge, J.M. (2007). "Inverse probability weighted estimation for general missing data problems". Journal of Econometrics I4I: I28I-I3OI

Wooldridge, J.M. (20I0). Econometric Analysis of Cross Section and Panel Data, 2nd ed. MIT Press, Cambridge, MA. 